\title{
The relationship between cardiac autonomic function and clinical and angiographic characteristics in patients with coronary artery disease
}

\author{
Relação entre a modulação autonômica cardíaca e as características \\ clínicas e angiográficas de pacientes com doença arterial coronariana
}

Vandeni C. Kunz', Raquel B. Souza², Anielle C. M. Takahashi', Aparecida M. Catai', Ester Silva',2

\begin{abstract}
Background: A reduction in heart rate variability (HRV) is considered an important indicator of autonomic dysfunction. Objectives: The aims of this study were to evaluate the presence of autonomic dysfunction measured by HRV in patients with coronary artery disease (CAD) and to compare them with normal subjects. Methods: A sample of 52 men (mean age $54 \pm 5.39$ years) was allocated into three groups: obstructive $C A D \geq 50 \%$ (CAD $n=18$ ), obstructive $C A D<50 \%$, (CAD- $n=17)$ and apparently healthy controls $(C G n=17)$. Heart rate (HR) was measured at rest using a Polar®S810i for $15 \mathrm{~min}$. HRV was analyzed via Shannon entropy (SE) and symbolic analysis (OV and 2ULV), which relate to sympathetic and vagal predominance, respectively. Statistical analysis included the Kruskal-Wallis test and multivariate analysis $(p<0.05)$. Results: The CAD+ group presented lower SE and 2 ULV\% values and higher OV\% compared to CADand control groups $(p<0.05)$. In the multivariate analysis, the presence of the clinical characteristics such as myocardial infarction and revascularization in the CAD+ group lead to a lower SE and higher OV compared to the CAD- group. The use of angiotensin converting enzymes led to a higher SE in the CAD- group compared to the CAD+ $(p<0.05)$. Conclusions: In uncomplicated CAD+ patients the patterns of HRV have a lower complexity, a greater sympathetic modulation and a lower parasympathetic modulation compared to CAD- and control groups in supine resting conditions. These results indicate that autonomic heart dysfunction is related to the degree of coronary occlusion and cardiac compromise.
\end{abstract}

Keywords: Physical therapy; heart rate; coronary artery disease; nonlinear dynamics.

\section{Resumo}

Contextualização: A redução da variabilidade da frequência cardíaca (VFC) é considerada como um importante marcador de disfunção autonômica. Objetivos: Avaliar a VFC em pacientes com doença arterial coronariana (DAC) e compará-los com sujeitos saudáveis.

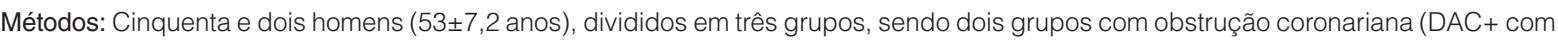
obstrução $\geq 50 \%, n=17$ e DAC+ com obstrução $\geq 50 \%, n=18$ ) e um grupo controle (GC, $n=17$ ). A frequência cardíaca (FC) foi captada batimento a batimento, a partir do Polar@S810i, em repouso supino, durante 15 minutos. A análise da VFC foi feita pelos cálculos da entropia de Shannon (ES) e pelos padrões da análise simbólica (OV e 2ULV\%), relacionados à predominância simpática e vagal, respectivamente. A análise estatística incluiu o teste de Kruskal-Wallis e a análise multivariada $(p<0,05)$. Resultados: $O$ grupo DAC+ apresentou menores valores de ES e 2ULV\% e maior OV quando comparado aos grupos DAC- e CG. Na análise multivariada, observouse menor ES e maior OV na presença das características clínicas prévias, como infarto e revascularização do miocárdio no grupo DAC+ comparado ao grupo DAC-. O uso de inibidores da enzima conversora de angiotensina contribuiu para maior ES do grupo DACcomparado ao DAC+. Conclusões: Na DAC+ não complicada, os padrões da VFC apresentam menor complexidade, maior modulação autonômica simpática e menor modulação parassimpática comparativamente ao DAC- e ao GC em repouso supino. Esses resultados indicam que a disfunção autonômica cardíaca está relacionada ao grau de oclusão coronariana e ao comprometimento cardíaco.

Palavras-chave: Fisioterapia; frequência cardíaca; doença arterial coronariana; dinâmica não-linear.

\section{Received: 08/12/2011 - Revised: 08/15/2011 - Accepted: 08/17/2011}

${ }^{1}$ Laboratory of Cardiovascular Physical Therapy, Nucleus of Research in Physical Exercise, Physical Therapy Department, Universidade Federal de São Carlos (UFSCar), São Carlos, SP, Brazil ${ }^{2}$ Faculty of Health Sciences, Universidade Metodista de Piracicaba (UNIMEP), Piracicaba, SP, Brazil

Correspondence to: Ester da Silva, Núcleo de Pesquisa em Exercício Físico, Departamento de Fisioterapia, Universidade Federal de São Carlos, Rodovia Washington Luis, Km 235, Caixa

Postal 676, CEP 13565-905, São Carlos, SP, Brasil, e-mail: esilvas@unimep.br; vandenikunz@yahoo.com.br 


\section{Introduction $: \because$.}

Physiological and environmental risk factors for developing coronary artery disease (CAD) such as smoking, obesity, sedentarism, arterial hypertension, diabetes and hypercholesterolemia, are well known. These risk factors alter autonomic function ${ }^{1-3}$, which is associated with both the progression of $\mathrm{CAD}^{4}$ and increased mortality in the general population ${ }^{5-7}$. This increased risk may be a result of electrical instability in the heart because of an unstable autonomic environment dominated by sympathetic nervous system influences ${ }^{8,9}$.

Alterations in the cardiac autonomic nervous system of $\mathrm{CAD}$ patients are related to the degree of coronary artery occlusion. These alterations result in a decrease in the vagal modulation and an increase in the sympathetic modulation ${ }^{10}$. Heart rate variability (HRV) has been extensively used to evaluate autonomic nervous system balance. A reduction in HRV is associated with an increased risk of $C A D^{4,11-13}$.

Traditionally, HRV has been analyzed both in time and frequency domains using linear methods ${ }^{5,12}$. However, it has been reported in the literature that heart rate (HR) dynamics are non-linear due to several oscillating subsystems that contribute through positive and negative feedback to the cardiovascular response. One of the most important subsystems is the autonomic nervous system, which modulates the $\mathrm{HR}^{14}$. Therefore, an analysis of non-linear HR dynamics using methods based on chaos theory has been proposed ${ }^{15,16}$. Porta et al. ${ }^{17}$ reported the analysis of non-linear HR dynamics using Shannon entropy (SE) analysis method, which calculates the degree of complexity of a series of RR interval (RRi) patterns. Studying the complexity of autonomic cardiac regulation could provide important information about the underlying regulation mechanisms ${ }^{18}$. Thus, modification to complexity indices could predict a pathological situation and a global depression of the organism ${ }^{18}$.

Another non-linear method that has been used to analyze sympathetic and parasympathetic systems is the symbolic analysis of a sequence of three heart beats, which allows to estimate the prevalence of each branch of the cardiac autonomic nervous system ${ }^{19}$. Thus, identifying alterations in the autonomic nervous system of CAD patients using non-linear methods such as SE and symbolic analysis may be useful for early evaluation and stratification of risk, as well as for the evaluation and monitoring of clinical vulnerability of new cardiac events and physical exercise in these patients.

Our hypothesis was that the degree of coronary occlusion is related to impairment of cardiac autonomic modulation and a reduction of complexity of sympathovagal balance. Therefore, the aims of this study were to determine via HRV the presence of autonomic dysfunction based on SE and symbolic analysis in patients with $\mathrm{CAD}$ and to determine if their HRV patterns are different from normal subjects.

\section{Methods $: \because$.}

\section{Participants}

A sample of $102 \mathrm{CAD}$ male patients was interviewed and was considered eligible for the study via angiography at the Hospital Coronary Care Unit. The following inclusion criteria were set for participation in the study: from one to four compromised arteries (anterior descending artery, left and right coronary arteries, left circumflex artery, marginal and diagonal branches); myocardial infarction and angioplasty in the past six months; myocardial revascularization surgery in the past 12 months; obesity (body mass index between 30 and $35 \mathrm{~kg} / \mathrm{m}^{2}$ ); smoking $^{20}$; drinking ${ }^{21}$; a low weekly level of physical activity according to the International Physical Activity Questionnaire (IPAQ) version $6^{22}$; history of high blood pressure ${ }^{23}$; history of dyslipidemia and diabetes mellitus.

Exclusion criteria included: frequent arrhythmias and extrasystoles $(n=5)$; obstructive pulmonary disease $(n=6)$; angioplasty carried out on the same day as the angiography $(\mathrm{n}=8)$; unstable angina $(\mathrm{n}=3)$; musculoskeletal disorders $(\mathrm{n}=5)$; insulin-dependent diabetes $(\mathrm{n}=6)$; systemic high blood pressure stages 2 and above $(n=5)$, neoplasia $(n=2)$, renal failure $(n=3)$, stroke sequelae $(n=4)$; use of beta blocker therapy $(n=15)$ and refusal to participate in the study $(\mathrm{n}=5)$.

Based on the inclusion and exclusion criteria 35 men were included in this study (mean age $55 \pm 6.02$ years). They were classified according to the results of the angiography as either $\mathrm{CAD}+(\mathrm{n}=18)$ or $\mathrm{CAD}-(\mathrm{n}=17)$, i.e. with or without significant stenosis ( $250 \%$ ) respectively, based on the Stable Angina Guide$\operatorname{lines}^{24}$ and a left ventricular ejection fraction (LVEF) within normality according to ventriculography $(\mathrm{CAD}+=56.27 \pm 5.45$ and $\mathrm{CAD}-=64.47 \pm 5.83$ ). The control group (CG) consisted of 17 healthy male volunteers (mean age $53 \pm 3.68$ years) whose medical status was certified by a full medical checkup including medical history, a physical examination, chest radiography, biochemical blood tests, electrocardiograms at rest and during exercise, and measurement of supine and standing blood pressure. The participants of the control group were also nonsmokers, non-drinkers, were not taking any type of medication, and were not drug users.

This study was approved by the Ethics Research Committee of the Universidade Metodista de Piracicaba (UNIMEP), Piracicaba, SP, Brazil (Number 04/09). All participants signed a consent form prior to the participation in the study. 


\section{Measurement and analysis of HRV}

All experiments were carried out in the afternoon in order to avoid response differences due to circadian changes. Room temperature was kept at $22{ }^{\circ} \mathrm{C}$ with relative air humidity between $40 \%$ and $60 \%$. The day before the experiment, the participants were taken to the experimental room for familiarization with the producers and the equipment to be used. Each subject was instructed to abstain from stimulants (coffee, tea, soft drinks), alcoholic beverages and excessive physical activity in the 24 hours prior to the exam, as well as to have a light meal at least 2 hours before the measurements.

To assess autonomic modulation, each subject's HR and RRi were measured for 15 minutes, captured digitally, and transferred to a computer for later analysis. All data were obtained before angioplasty using a Polar Advanced S810i ${ }^{\circledR}$ HR monitor and a transmitter belt (Polar Electro Co.Ltda. Kempele, Finland). All subjects were carefully instructed and the measurements were taken in the presence of the chief investigator of the study. The participants were resting, awake and in supine position with their hands lying at their sides. After resting for 15 minutes, blood pressure and HR were measured to determine whether the basal conditions of the subjects were adequate for the experiment. The HR monitor registered RRi via a transmitter attached to the thorax and a wristband.

$\mathrm{HR}$ monitors provide information recording RRi, which is defined as the time interval between two adjacent QRS complexes (the extension of the heart cycle). The Polar Advanced S810i detects the RR waves from the electrocardiogram with a $500 \mathrm{~Hz}$ sampling frequency and one-millisecond time resolution $^{25}$. After transferring the data to the computer, the RRi series were analyzed and any interference was eliminated. For this measurement, the region of the greatest stability for gathering RRi was used so that 300 consecutive beats from the same time segment were presented for all paticipants ${ }^{12}$. To analyze HRV, SE and symbolic analysis were used, both of which have been fully described and validated previously ${ }^{17}$.

\section{Symbolic analysis}

This approach, which has been described by Porta et al. ${ }^{17}$, is based on 1) transforming a heart period variability series into a sequence of integers (i.e., symbols), 2) constructing patterns (i.e., words), 3) reducing the number of patterns by grouping them into a small number of families, and 4) evaluating the rates of occurrence of these families. A coarse-graining approach based on a uniform quantization procedure was used to transform the RR series into a sequence of symbols. Briefly, the full range of the series was spread over $\xi$ symbols with a resolution of (RRmax-RRmin)/ $\xi$, where RRmax and RRmin were the maximum and the minimum of the series. After quantization, the $R R$ series became a sequence $R R_{\xi}=\left\{R R_{\xi}(i)\right.$, $\mathrm{i}=1, \ldots, \mathrm{N}\}$ of integer values ranging from 0 to $\xi-1^{17}$. The technique of delayed coordinates was used to transform the $\mathrm{RR}_{\xi}$

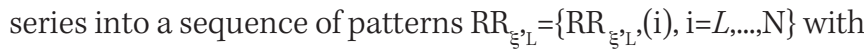
$\mathrm{RR}_{\xi_{\mathrm{L}}}(\mathrm{i})=\left[\mathrm{RR}_{\xi}(\mathrm{i}), \mathrm{RR}_{\xi}(\mathrm{i}-1), \ldots, \mathrm{RR}_{\xi}(\mathrm{i}-L+1)\right]$. The number of possible $R R_{\xi_{L}}(i)$ was $\xi^{L}$. Since $\xi^{L}$ grew very rapidly with $L$ and $\xi$, both parameters had to be small. For applications over short data sequences, the best compromise was $\xi=6$ and $\mathrm{L}=3$, and the number of possible patterns was $216^{17}$.

To reduce the number of patterns without losing information, we followed a procedure of redundancy reduction. All the patterns were grouped without loss into four families, according to the number and types of variations from one symbol to the next. The pattern families were as follows: 1) patterns with no variation [0V: all the symbols are equal, e.g., $(4,4,4)$ or $(2,2,2)], 2)$ patterns with one variation [1V: 2 consecutive symbols are equal and the remaining symbol is different, e.g., $(3,4,4)$ or $(4,4,2)], 3)$ patterns with two like variations [2LV: the 3 symbols form an ascending or descending ramp, e.g., $(1,2,4)$ or $(4,3,2)]$, and 4) patterns with two unlike variations [2ULV: the 3 symbols form a peak or a valley, e.g., $(2,4,2)$ or $(4,1,2)]^{17}$. We evaluated the rates of occurrence of these families, which were designated $0 \mathrm{~V} \%, 1 \mathrm{~V} \%, 2 \mathrm{LV} \%$, and $2 \mathrm{ULV} \%$. To compute these indices, we simply count the number of times a pattern $R_{\xi=6, L=3}(i)$ belonging to a specific family was found in $\mathrm{RR}_{\xi=6, \mathrm{~L}=3}$. The result (multiplied by 100) was divided by $[\mathrm{N}-(L-1)]^{17}$.

Studies with pharmacological blockade ${ }^{19}$ and autonomic tests have indicated that $0 \mathrm{~V} \%$ and $2 \mathrm{ULV} \%$ indices are able to assess sympathetic and parasympathetic modulations, respectively.

\section{Shannon Entropy (SE) analysis}

The SE of the pattern distribution was calculated to provide a description of pattern distribution complexity, i.e., SE is an index describing the shape of the distribution of the patterns. The SE is large if the distribution is flat (all patterns are identically distributed and the series carries the maximum amount of information). On the other hand, the SE is small if there is a probable subset of patterns, while others are missing or infrequent (e.g., in a Gaussian distribution) $)^{17,26}$.

\section{Data analysis}

The series length $\mathrm{N}$ was fixed at 300 beats. The mean $\mathrm{RR}$ and the variance of the RR series were calculated. 


\section{Statistical analysis}

For the between-group analysis of the SE data and the OV and 2ULV patterns, the Kruskal-Wallis test with Dunn's post hoc was used. The HRV (SE, OV and 2ULV) relationship with covariant clinical characteristics (myocardial infarction $>6$ months, myocardial revascularization $>12$ months, angioplasty $>6$ months, number of diseased vessels and location of stenosis), risk factors (hypertension, diabetes mellitus, dyslipidemia, family predisposition to CAD, obesity, smoking and drinking) and medications angiotensin converting enzyme (ACE) inhibitors, hypolipidemic, hypoglycemic, diuretics and antiplatelet) was analyzed with the multivariate test model type III and Bonferroni post hoc. The significance level was set at $5 \%$ for all analysis $(\mathrm{p}<0.05)$. The programs SPSS 13.0 for Windows and Statistica for Windows v 6.1 (Stat Soft, Inc. 2000-2003) were used. A study-power analysis suggested that a minimum of 14 subjects analyzed in each group and a 5\% significance level (two-tailed) would yield at least $80 \%$ power for detecting differences between the variables SE, $0 \mathrm{~V}$ and $2 \mathrm{ULV}$.

\section{Results $: \because$.}

\section{Clinical characteristics}

Table 1 shows the baseline characteristics and cardiovascular parameters of participants which can be observed that the three groups were similar, including systolic and diastolic blood pressure (SBP and DBP) (mmHg), HR (bpm), RRi (ms) and estimated LVEF (\%) results at rest in the supine position. There was a statistically significant difference between the $\mathrm{CAD}+$ and $\mathrm{CG}$ for HR $(\mathrm{p}<0.05)$. However, there were no significant differences for the other variables ( $p>0.05)$.

Table 1. Clinical characteristics of the participants at baseline.

\begin{tabular}{lccc}
\hline \multicolumn{1}{c}{ Variables } & $\begin{array}{c}\text { CAD+ } \\
\mathrm{n}=18\end{array}$ & $\begin{array}{c}\text { CAD- } \\
\mathrm{n}=17\end{array}$ & $\begin{array}{c}\text { Control } \\
\mathrm{n}=17\end{array}$ \\
\hline Age (years) & $57 \pm 4.86$ & $52 \pm 6.11$ & $53 \pm 3.68$ \\
\hline Weight $(\mathrm{kg})$ & $79.81 \pm 14.59$ & $78.44 \pm 15.68$ & $76.12 \pm 6.43$ \\
\hline Height $(\mathrm{m})$ & $1.67 \pm 0.07$ & $1.70 \pm 0.04$ & $1.73 \pm 0.04$ \\
\hline BMl $\left(\mathrm{kg} / \mathrm{m}^{2}\right)$ & $28.29 \pm 4.52$ & $26.68 \pm 4.04$ & $25.19 \pm 1.65$ \\
\hline SBP $(\mathrm{mmHg})$ & $133.33 \pm 14.95$ & $121.17 \pm 10.53$ & $120 \pm 11.18$ \\
\hline DBP $(\mathrm{mmHg})$ & $84.16 \pm 8.08$ & $81.17 \pm 7.81$ & $78.23 \pm 6.35$ \\
\hline HR (beats/min) & $72.11 \pm 7.51^{*}$ & $65.70 \pm 8.09$ & $63.11 \pm 4.83$ \\
\hline RR intervals $(\mathrm{ms})$ & $890.65 \pm 138.91$ & $903.50 \pm 136.37$ & $948.32 \pm 91.70$ \\
\hline Estimated LVEF $(\%)$ & $56.27 \pm 5.45$ & $64.47 \pm 5.83$ & -- \\
\hline
\end{tabular}

Mean $\pm S D$ for continuous variables. CAD+=patients with significant coronary artery stenosis ( $>50 \%)$; CAD-=patients without significant coronary artery stenosis $(<50 \%)$; $\mathrm{SBP}=$ systolic blood pressure; $\mathrm{DBP}=$ diastolic blood pressure; HR=heart rate; $\mathrm{LVEF}=$ left ventricular ejection fraction. ${ }^{*} p<0.05$ (CAD+ group vs control group).
Data regarding the participants' clinical characteristics, risk factors and medication used by group are presented in Table 2.

\section{Heart rate variability indices}

Figure 1A shows HRV analysis via SE and symbolic analysis; the between-group analysis presented statistically significant differences. $\mathrm{SE}$ in the $\mathrm{CAD}+$ group was significantly lower than in CAD- and CG (3.28, 3.51 and 3.53, respectively, $\mathrm{p}<0.05)$. The $0 \mathrm{~V}$ pattern was lower in $\mathrm{CG}$ and CAD- than the CAD+ group (24.74, 26.08 and 31.26, respectively, $p<0.01$ ) (Figure $1 \mathrm{~B}$ ), and the 2ULV pattern was lower in the CAD+ group than both the CAD- and CG (12.54, 16.72 and 19.69, respectively, $\mathrm{p}<0.05$ ) (Figure $1 \mathrm{C}$ ).

\section{Multivariate analysis}

Regarding the relationship between group means, according to the data from the HRV analysis and the presence

Table 2. Clinical and angiographic data, risk factors and medications.

\begin{tabular}{lccc}
\hline Clinical Characteristics & $\begin{array}{c}\text { CAD+ } \\
\text { yes/no }\end{array}$ & $\begin{array}{c}\text { CAD- } \\
\text { yes/no }\end{array}$ & $\begin{array}{c}\text { Control } \\
\text { yes/no }\end{array}$ \\
\hline Myocardial infarction (>6 months) & $4 / 14$ & $0 / 17$ & $0 / 17$ \\
\hline Myocardial revascularization (>12 months) & $6 / 12$ & $0 / 17$ & $0 / 17$ \\
\hline Angioplasty (>6 months) & $4 / 14$ & $0 / 17$ & $0 / 17$ \\
\hline No. of diseased vessels & & & \\
\hline One diseased vessel & $6 / 12$ & $11 / 6$ & $0 / 17$ \\
\hline Two diseased vessels & $5 / 13$ & $6 / 11$ & $0 / 17$ \\
\hline Three or four diseased vessels & $8 / 10$ & $0 / 17$ & $0 / 17$ \\
\hline Location of stenosis & & & \\
\hline Anterior descending artery & $14 / 4$ & $11 / 6$ & $0 / 17$ \\
\hline Right coronary artery & $11 / 7$ & $6 / 11$ & $0 / 17$ \\
\hline Left circumflex artery & $5 / 13$ & $2 / 15$ & $0 / 17$ \\
\hline Marginal arteries & $7 / 11$ & $3 / 14$ & $0 / 17$ \\
\hline Diagonal arteries & $7 / 11$ & $0 / 17$ & $0 / 17$ \\
\hline Risk factors & & & \\
\hline Hypertension & $15 / 3$ & $6 / 11$ & $0 / 17$ \\
\hline Diabetes mellitus & $9 / 9$ & $2 / 15$ & $0 / 17$ \\
\hline Dyslipidemia & $11 / 7$ & $8 / 9$ & $0 / 17$ \\
\hline Family predisposition to CAD & $9 / 9$ & $4 / 13$ & $0 / 17$ \\
\hline Overweight (BMl between 25 and 30 kg/m²) & $7 / 11$ & $5 / 12$ & $5 / 12$ \\
\hline Obesity (BMl > 30 kg/m²) & $7 / 11$ & $4 / 13$ & $0 / 17$ \\
\hline Smoking & $6 / 12$ & $3 / 14$ & $0 / 17$ \\
\hline Drinking & $2 / 16$ & $3 / 14$ & $0 / 17$ \\
\hline Medications & & \\
\hline ACE-inhibitors & $7 / 11$ & $6 / 11$ & $0 / 17$ \\
\hline Hypolipidemic & $10 / 8$ & $4 / 13$ & $0 / 17$ \\
\hline Hypoglycemic & $6 / 12$ & $2 / 15$ & $0 / 17$ \\
\hline Diuretics & $6 / 12$ & $2 / 15$ & $0 / 17$ \\
\hline Antiplatelet & $16 / 2$ & $5 / 12$ & $0 / 17$ \\
\hline CAD & & & \\
\hline
\end{tabular}

$C A D+=$ patients with significant coronary artery stenosis; $C A D$-=patients without significant coronary artery stenosis; $\mathrm{ACE}=$ angiotensin-converting enzyme. 
of clinical characteristics, risk factors and medications used (shown in Table 3); it was observed that among patients of the $\mathrm{CAD}+$ group who had a history of infarction and myocardial revascularization, the SE values were lower and the $0 \mathrm{~V}$ pattern was higher compared to the CAD- group $(\mathrm{p}<0.05)$. Regarding the use of ACE inhibitors, the patients from the CAD- group who used this medication presented higher SE compared to the CAD+ group $(\mathrm{p}<0.05)$. However, the $2 \mathrm{ULV}$ pattern presented no relationship with clinical characteristics, risk factors or medications.

Table 3. Multivariate analysis of mean between groups, according heart rate variability variables and the presence of clinical characteristics, risk factors and medications.

\begin{tabular}{|c|c|c|c|}
\hline Clinical & & Variables & \\
\hline Characteristics & SE & OV & 2ULV \\
\hline $\begin{array}{l}\text { Myocardial infarction } \\
\text { (>6 months) }\end{array}$ & ns & $\begin{array}{l}\text { CAD+> CAD- } \\
\text { and control* }\end{array}$ & ns \\
\hline $\begin{array}{l}\text { Myocardial revasculariza- } \\
\text { tion (>12 months) }\end{array}$ & ns & $\begin{array}{l}\text { CAD+ > CAD- } \\
\text { and control* }\end{array}$ & ns \\
\hline Angioplasty (>6 months) & ns & ns & ns \\
\hline No. of diseased vessels & & & \\
\hline One vessel disease & ns & ns & ns \\
\hline Two vessel disease & ns & ns & ns \\
\hline $\begin{array}{l}\text { Three or four vessel } \\
\text { disease }\end{array}$ & ns & ns & ns \\
\hline Location of stenosis & & & \\
\hline Anterior descending artery & ns & ns & ns \\
\hline Right coronary artery & ns & ns & ns \\
\hline Letf circunflex artery & ns & ns & ns \\
\hline Marginal arteries & ns & ns & ns \\
\hline Diagonal arteries & ns & ns & ns \\
\hline Risk factors & & & \\
\hline Hipertension & ns & ns & ns \\
\hline Diabetes mellitus & ns & ns & nS \\
\hline Dyslipidemia & ns & ns & nS \\
\hline $\begin{array}{l}\text { Familial predisposition } \\
\text { to CAD }\end{array}$ & ns & ns & ns \\
\hline $\begin{array}{l}\text { Overweight (BMI betwen } \\
25 \text { and } 30 \mathrm{~kg} / \mathrm{m}^{2} \text { ) }\end{array}$ & ns & ns & nS \\
\hline Obesity $\left(\mathrm{BMI}>30 \mathrm{~kg} / \mathrm{m}^{2}\right)$ & ns & ns & ns \\
\hline Smoking & ns & ns & ns \\
\hline Drinking & ns & ns & ns \\
\hline Medications & & & \\
\hline ACE-inhibitors & $\begin{array}{l}\text { CAD+< } \\
\text { CAD-* }\end{array}$ & ns & ns \\
\hline Hypolipidemic & ns & ns & ns \\
\hline Hypoglycemic & ns & ns & ns \\
\hline Diuretics & ns & ns & ns \\
\hline Antiplatelet & ns & ns & ns \\
\hline
\end{tabular}

$S E=S h a n n o n$ entropy; $O V=$ patterns with no variation; $2 U L V=$ patterns with two unlike variations; $\mathrm{CAD}+=$ patients with significant coronary artery stenosis; $\mathrm{CAD}-=$ patients without significant coronary; Control=control group; $\mathrm{ACE}=$ angiotensin-converting enzyme; ns=not statistically significant. ${ }^{*} p<0.05$.

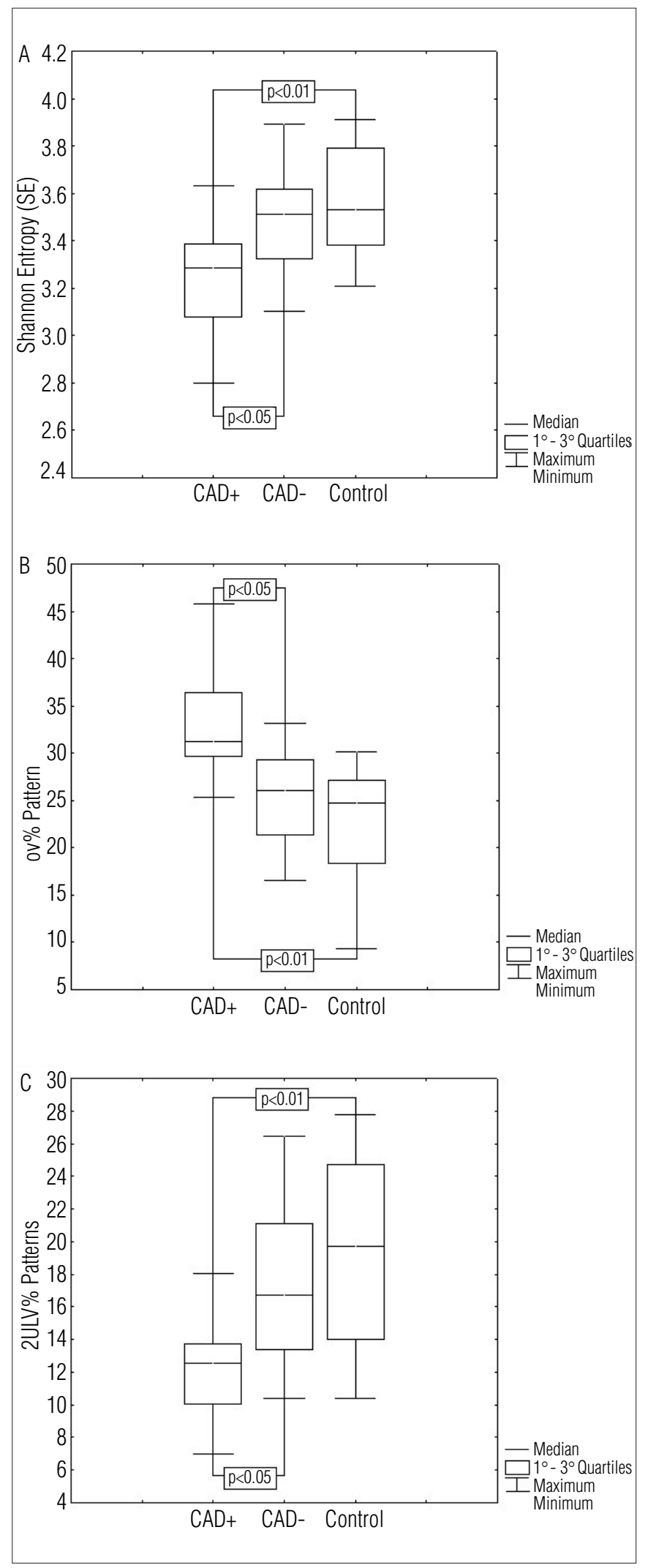

Figure 1. Box Plot (Median, $1^{\circ}$ and $3^{\circ}$ quartiles, minimum and maximum) showing results of Shannon entropy $(1 \mathrm{~A})$ and symbolic analysis (OV, patterns with no variation (1B) and 2ULV, patterns with two unlike variations $(1 C)$ ) in the $C A D+$ (patients with significant coronary artery stenosis), CAD- (patients without significant coronary) and control groups. 


\section{Discussion $: \because$.}

The results of this study, based on SE and symbolic analysis, indicate presence of autonomic heart dysfunction in $\mathrm{CAD}$ patients with $\geq 50 \%$ occlusion compared to either CAD patients with $<50 \%$ obstruction and normal subjects.

$\mathrm{SE}$ is a measure of the complexity of the distribution of the sample of a signal ${ }^{17}$. Our results suggest that the complexity of autonomic HR modulation is related to the severity of coronary occlusion, given that the $\mathrm{CAD}+$ group presented a reduction in $\mathrm{SE}$ compared to $\mathrm{CAD}$ - and control groups. A reduction in $\mathrm{SE}$ is related to cardiac sympatho-vagal imbalance, which can predict global depression as well as other pathological situations ${ }^{18}$. Voss et al. ${ }^{27}$ observed a decrease in SE patterns in patients after myocardial infarction, which is related to an increase in the risk of malignant arrhythmias and sudden cardiac death.

In our study, $\mathrm{CAD}+$ patients presented lower $\mathrm{SE}$ as well as alterations in symbolic analysis patterns, with a decrease in the $2 \mathrm{ULV}$ pattern and an increase in the $0 \mathrm{~V}$ pattern compared to the CAD- and control groups. The $0 \mathrm{~V}$ patterns are features of slow waves (LF oscillations), while 2LV and 2ULV patterns are fragments of faster waves (HF oscillations) ${ }^{17}$. Symbolic patterns have been linked to sympathetic and vagal cardiac modulation in previous studies with pharmacological blockade and autonomic tests in healthy and diseased populations ${ }^{19,26,28,29}$. The $0 \mathrm{~V}$ pattern has been associated with sympathetic modulation while $2 \mathrm{ULV}$ has been associated with vagal modulation ${ }^{19,29}$. Therefore, our results suggest that patients from the CAD+ group have increased sympathetic modulation and decreased vagal modulation, which are related to the severity of the coronary occlusion.

These findings agree with previous studies involving linear methods, which observed that coronary insufficiency led to dysfunction of the autonomic modulation of HR characterized by an increase in sympathetic modulation or a decrease in vagal modulation ${ }^{30-32}$.

The imbalance in autonomic modulation that accompanies $\mathrm{CAD}$ is due to increased sympathetic adrenergic tone and reduced parasympathetic activity, which causes augmented ventricular workload and oxygen demand, thus increasing the occurrence of ischemic events, and causes modification to the ionic currents across the cellular membrane, leading to direct electrical instability of myocytes ${ }^{30}$. It is known that abnormal autonomic function predisposes arrhythmias under various clinical and experimental conditions, particularly during physical stress. Therefore, important prognostic information about the appearance of undesirable events, including cardiac mortality, can be obtained from an analysis of HRV indices ${ }^{10,27}$.

Regarding the relationship between variables obtained from the HRV analysis and clinical characteristics, risk factors and the use of medication, the results demonstrated that patients from the $\mathrm{CAD}+$ group who had a previous history of myocardial infarction and revascularization presented lower SE and higher OV pattern than the CAD- group. This means that, even six months after AMI and the revascularization period, these two clinical characteristics associated with the degree of coronary occlusion were the ones that most contributed to the decrease of complexity in autonomic modulation and to the increase in sympathetic modulation. This corroborates the finding of longitudinal studies that have evaluated patients after $\mathrm{AMI}^{33-35}$ or myocardial revascularization surgery ${ }^{36,37}$ that autonomic dysfunction could be present up to 12 months after a coronary event.

Upon analyzing the relationship between HRV variables and medication use, it was observed that there was a higher SE value for patients from the $\mathrm{CAD}$ - group compared to the $\mathrm{CAD}+$ group when subjects who used ACE inhibitors were considered. This reflects a greater complexity of RRi series for patients from the CAD- group. Due to the inhibition of angiotensin II functions along with the consequent attenuation of vasoconstriction and sympathetic activity ${ }^{38}$ ACE inhibitors lead to significant recovery of HRV indices, as observed through linear methods, which implies an improvement in the autonomic modulation of HR and a satisfactory prognosis ${ }^{39}$.

Thus, in general terms, the results of the present study show those patients from the $\mathrm{CAD}+$ group, even after myocardial revascularization and the use of ACE inhibitors, present higher sympathetic autonomic modulation, suggesting that they may be more vulnerable to develop new cardiovascular events.

\section{Limitations}

This study was limited by the difficulty in selecting a sample that fulfilled the proposed inclusion criteria, as well as by the heterogeneity of the patient sample. Due to such factors, myocardial infarction and revascularization influenced the results.

\section{Clinical and practical implications}

The results of this study demonstrate that in CAD patients there is a reduction in the complexity of cardiovascular regulation due to a reduction in autonomic vagal modulation and an increase in sympathetic autonomic modulation. Thus, evaluating the autonomic modulation of HR by SE and symbolic analysis contributes to the identification of alterations in HR autonomic modulation and could provide useful clinical information without the need for additional sophisticated analysis. Furthermore, HRV analysis becomes relevant for both early screening and risk stratification for heart disease as well as for the clinical follow-up of patients who are known to have CAD. 
Furthermore, the objective of introducing HRV analysis by means of SE and symbolic analysis is to encourage the use of this non-invasive technique in the area of cardiac rehabilitation, making it possible to evaluate and reevaluate HR autonomic modulation before and after physical therapy interventions.

\section{Conclusions $: \because 8$}

In uncomplicated $\mathrm{CAD}+$, the patterns of HRV presented lower complexity of HR autonomic modulation, higher sympathetic modulation and lower parasympathetic modulation in basal conditions. These results indicate that autonomic heart dysfunction is associated with the severity of coronary occlusion. However, this issue requires further studies with larger patient populations.

\section{Acknowledgements $: \because$.}

To Dr. Alberto Porta for providing program analysis of SE and symbolic analysis. This work was supported by the Conselho Nacional de Desenvolvimento Científico e Tecnológico (579408/2008-6 and 308348/2009-5) and Coordenação de Aperfeiçoamento de Pessoal de Nivel Superior (0021058210).

\section{References : $:$.}

1. Mussalo H, Vanninen $E$, lkäheimo R, Laitinen $T$, Laakso $M$, Länsimies $E$, et al. Heart rate variability and its determinants in patients with severe or mild essential hypertension. Clin Physiol. 2001;21(5):594-604.

2. Pehlivanidis AN, Athyros VG, Demitriadis DS, Papageorgiou AA, Bouloukos VJ, Kontopoulos $A G$. Heart rate variability after long-term treatment with atorvastatin in hypercholesterolaemic patients with or without coronary artery disease. Atherosclerosis. 2001;157(2):463-9.

3. Vaccarino V, Lampert R, Bremner JD, Lee F, Su S, Maisano C, et al. Depressive symptoms and heart rate variability: evidence for a shared genetic substrate in a study of twins. Psychosom Med. 2008;70(6):628-36

4. Huikuri HV, Jokinen V, Syvänne M, Nieminen MS, Airaksinen KE, Ikäheimo MJ, et al. Heart rate variability and progression of coronary atherosclerosis. Arterioscler Thromb Vasc Biol. 1999;19(8):1979-85

5. Akselrod S, Gordon D, Ubel FA, Shannon DC, Berger AC, Cohen RJ. Power spectrum analysis of heart rate fluctuation: a quantitative probe of beat-to-beat cardiovascular control. Science. 1981;213(4504):220-2

6. Liao D, Cai J, Rosamond WD, Barnes RW, Hutchinson RG, Whitsel EA, et al. Cardiac autonomic function and incident coronary heart disease: a population-based case-cohort study. Am J Epidemiol. 1997;145(8):696-706.

7. Tsuji H, Larson MG, Venditti FJ Jr, Manders ES, Evans JC, Feldman CL, et al. Impact of reduced heart rate variability on risk for cardiac events. The Framingham Heart Study. Circulation. 1996;94(11):2850-5

8. Kleiger RE, Miller P, Bigger JT Jr, Moss AJ. Decreased heart rate variability and its association with increased mortality after acute myocardial infarction. Am J Cardiol. 1987;59(4):256-62.

9. Huikuri HV, Mäkikallio TH. Heart rate variability in ischemic heart disease. Auton Neurosci. 2001;90(1-2):95-101.

10. Wennerblom B, Lurje L, Tygesen $H$, Vahisalo R, Hjalmarson A. Patients with uncomplicated coronary artery disease have reduced heart rate variability mainly affecting vagal tone. Heart. 2000;83(3):290-4

11. Bigger JT Jr, Fleiss JL, Steinman RC, Rolnitzky LM, Kleiger RE, Rottman JN. Frequency domain measures of heart period variability and mortality after myocardial infarction. Circulation. 1992:85:164-71.

12. Heart rate variability: standards of measurement, physiological interpretation and clinical use. Task Force of the European Society of Cardiology and the North American Society of Pacing and Electrophysiology. Circulation. 1996;93(5):1043-65.

13. Novais LD, Sakabe DI, Takahashi ACM, Gongora H, Taciro C, Martins LEB, et al. Avaliação da variabilidade da frequência cardíaca em repouso de homens saudáveis, sedentários e hipertensos e de coronariopatas em treinamento físico. Rev Bras Fisioter. 2004;8(3):207-13.

14. Signorini MG, Marchetti F, Cerutti S. Applying nonlinear noise reduction in the analysis of heart rate variability. IEEE Eng Med Biol Mag. 2001;20(2):59-68.

15. Goldberger AL, Amaral LA, Glass L, Hausdorff JM, Ivanov PC, Mark RG, et al. PhysioBank, Physio Toolkit, and PhysioNet: components of a new research resource for complex physiologic signals. Circulation. 2000;101(23):E215-20.
16. Freitas $U$, Roulin $\mathrm{E}$, Muir JF, Letellier $\mathrm{C}$. Identifying chaos from heart rate: the right task? Chaos 2009;19(2):028505.

17. Porta A, Di Rienzo MD, Wessel N, Kurths J. Addressing the complexity of cardiovascular regulation. Philos Transact A Math Phys Eng Sci. 2009;367(1892):1215-8.

18. Porta A, Guzzetti S, Montano N, Furlan R, Pagani M, Malliani A, et al. Entropy, entropy rate, and pattern classification as tools to typify complexity in short heart period variability series. IEEE Trans Biomed Eng. 2001;48(11):1282-91

19. Guzzetti S, Borroni E, Garbelli PE, Ceriani E, Bella PD, Montano N, et al. Symbolic dynamics of heart rate variability: a probe to investigate cardiac autonomic modulation. Circulation. 2005;112(4):465-70.

20. Iglesias R, Jha P, Pinto M, Silva VLC, Godinho J. Controle do tabagismo no Brasil. Washingtoin DC: Banco Mundial; 2007

21. Gaziano JM, Hennekens C. Royal colleges' advice on alcohol consumption: maintaining existing limits seems justified on current evidence. BMJ. 1995;311(6996):3-4.

22. Hallal PC, Victora CG. Reliability and validity of the International Physical Activity Questionnaire (IPAQ). Med Sci Sports Exerc. 2004;36(3):556

23. Mion Jr D, Kohlmann Jr O, Machado CA, Amodeo C, Gomes MAM, Praxedes JN, et al. V Diretrizes brasileiras de hipertensão arterial. Arq Bras Cardiol. 2007;89(3):e24-79.

24. Diretrizes de doença coronariana crônica angina estável. Arq Bras Cardiol. 2004;83 Sup II:1-43.

25. Gamelin FX, Berthoin S, Bosquet L. Validity of the polar S810 heart rate monitor to measure R-P intervals at rest. Med Sci Sports Exerc. 2006;38(5):887-93.

26. Takahashi ACM, Porta A, Melo RC, Quitério RJ, da Silva E, Borghi-Silva A, et al. Aging reduces complexity of heart rate variability assessed by conditional entropy and symbolic analysis. Intern Emerg Med. 2011; DOI: 10.1007/s11739-011-0512-z.

27. Voss A, Kurths J, Kleiner HJ, Witt A, Wessel N, Saparin P, et al. The application of methods of non-linear dynamics for the improved and predictive recognition of patients threatened by sudden cardiac death. Cardiovasc Res. 1996;31(3):419-33.

28. Maestri R, Pinna GD, Accardo A, Allegrini P, Balocchi R, D'Addio G, et al. Nonlinear indices of heart rate variability in chronic heart failure patients: redundancy and comparative clinical value. J Cardiovasc Electrophysiol. 2007;18(4):425-33.

29. Porta A, Tobaldini E, Guzzetti S, Furlan R, Montano N, Gnecchi-Ruscone T. Assessment of cardiac autonomic modulation during graded head-up tilt by symbolic analysis of heart rate variability. Am J Physiol Heart Circ Physiol. 2007;293(1):H702-8.

30. La Rovere MT, Bigger JT Jr, Marcus FI, Mortara A, Schwartz PJ. Baroreflex sensitivity and heart-rate variability in prediction of total cardiac mortality after myocardial infarction. ATRAM (Autonomic Tone and Reflexes After Myocardial Infarction) Investigators. Lancet 1998;351(9101): 478-84.

31. Kuo CD, Chen GY. Comparison of three recumbent positions on vagal and sympathetic modulation using spectral heart rate variability in patients with coronary artery disease. Am J Cardiol. 1998;81(4):392-6. 
32. Abildstrom SZ, Jensen BT, Agner E, Torp-Pedersen C, Nyvad O, Wachtell K, et al. Heart rate versus heart rate variability in risk prediction after myocardial infarction. J Cardiovasc Electrophysiol. 2003;14(2):168-73

33. Binkley PF, Orsinelli DA, Nunziata E, Patterson SP, Khot UN, Puri R, et al. Differing autonomic response to dobutamine in the presence and absence of ischemia: implications for the autonomic contribution to positive inotropic intervention. Am Heart J. 1995;130(5): 1054-61.

34. Kleiger RE, Stein PK, Bosner MS, Rottman JN. Time domain measurements of heart rate variability. Cardiol Clin. 1992;10(3):487-98

35. Perkiömäki JS, Hämekoski S, Junttila MJ, Jokinen V, Tapanainen J, Huikuri HV. Predictors of long-term risk for heart failure hospitalization after acute myocardial infarction. Ann Noninvasive Electrocardiol. 2010;15(3):250-8.
36. Santangeli P, Sgueglia GA, Sestito A, Lamendola P, Mariani L, Infusino F, et al. Different effect of percutaneous and surgical coronary revascularization on cardiac autonomic function and inflammation in patients with stable angina. Int J Cardiol. 2008;127(2):269-70.

37. Laitio TT, Huikuri HV, Koskenvuo J, Jalonen J, Mäkikallio TH, Helenius H, et al. Long-term alterations of heart rate dynamics after coronary artery bypass graft surgery. Anesth Analg. 2006;102(4):1026-31

38. Dibner-Dunlap ME, Smith ML, Kinugawa T, Thames MD. Enalaprilat augments arterial and cardiopulmonary baroreflex control of sympathetic nerve activity in patients with heart failure. J Am Coll Cardiol. 1996;27(2):358-64.

39. Lewandowski J, Abramczyk P, Dobosiewicz A, Bidiuk J, Sinski M, Gaciong Z. The effect of enalapril and telmisartan on clinical and biochemical indices of sympathetic activity in hypertensive patients. Clin Exp Hypertens. 2008:30(5):423-32. 